Al-Madrasah: Jurnal Ilmiah Pendidikan Madrasah Ibtidaiyah

Vol. 6, No. 1, 2022

DOI 10.35931/am.v6i1.914

P-ISSN: 2620-5807; E-ISSN: 2620-7184

\title{
PENGARUH PENDIDIKAN KARAKTER BELA NEGARA TERHADAP ANCAMAN NYATA KE DEPAN
}

\author{
Harlis Setiyowati $^{1}$ \& Nurhaliza Vania Akbariani ${ }^{2}$ \\ Dosen Universitas Pradita ${ }^{1}$ \\ Scientia Business Park, Jl. Gading Serpong Boulevard No.1, Tangerang 15810 \\ Mahasiswa STT Terpadu Nurul Fikri \\ Correspondence email: harlis.setiyowati@pradita.ac.id. ${ }^{1}$ https://orcid.org/0000-0003- \\ 3773-3454
}

\begin{abstract}
Abstrak
Sekolah Master adalah penyelenggara pendidikan layanan khusus bagi anak-anak jalanan dengan dua versi yaitu versi Sekolah Terbuka dan versi PKBM (Pusat Kegiatan Belajar Masyarakat) terdiri dari Paket A, B dan C juga PAUD dan TK. Master singkatan dari Masjid Terminal karena lokasi sekolah berada pada lingkungan terminal Depok dan Masjid tempat awal sebelum memiliki gedung sendiri. Sekolah Master, tentu perlu pendampingan secara terus menerus, baik secara Pendidikan formal maupun Pendidikan non formal. Tujuan penelitian ini adalah upaya untuk mengurangi ancaman nyata kedepan melalui penguatan pendidikan karakter bela negara (PPKBN). PPKBN dilaksanakan di lingkungan sekolah, lingkungan keluarga, lingkungan masyarakat dan di lingkungan Negara. Metode penelitian ini menggunakan pendekatan kuantitatif dan kualitatif dengan metode survei. Hasil olah data SPSS versi 25 yaitu variabel PPKBN Di Lingkungan Masyarakat $\left(X_{3}\right)$ lebih besar dari variabel PPKBN Di Lingkungan Negara $\left(X_{4}\right)$, diikuti oleh variabel PPKBN Di Lingkungan Sekolah $\left(X_{1}\right)$ dan variabel PPKBN Di Lingkungan Keluarga $\left(X_{2}\right)$. Semakin tinggi kualitas PPKBN Di Lingkungan Masyarakat maka akan sangat kuat dengan tingginya kualitas Pengurangan Ancaman Nyata Ke Depan (Y) itu sendiri.

Kata Kunci : Ancaman, Bela Negara, Pendidikan Karakter.
\end{abstract}

\section{PENDAHULUAN}

Berdasarkan UUD 1945 Pasal 30 ayat (1) dan (2), yang perlu dipahami yaitu 1) Keikutsertaan warga negara dalam pertahanan dan keamanan negara merupakan hak dan kewajiban; 2) Pertahanan dan keamanan negara menggunakan sistem pertahanan dan keamanan rakyat semesta; 3) Kekuatan utama dalam sistem pertahanan adalah TNI, sedangkan dalam sistem keamanan adalah POLRI; 4) Kedudukan rakyat dalam pertahanan dan keamanan sebagai kekuatan pendukung. Bela Negara dalam arti luas tidak hanya dalam menghadapi ancaman militer tetapi juga non militer, di era globalisasi dan pesatnya kemajuan ilmu pengetahuan dan teknologi, bentuk ancaman sangat variative dan kompleks, hanya bangsa yang mempunyai keunggulan kompetitif lah yang mampu bersaing dan memenangkan persaingan tersebut Pendidikan

Al-Madrasah: Jurnal Ilmiah Pendidikan Madrasah Ibtidaiyah Vol. 6, No. 1, Januari-Maret 2022 
Harlis Setiyowati, Nurhaliza Vania Akbariani : Pengaruh Pendidikan Karakter Bela Negara Terhadap Ancaman Nyata Ke Depan

Kewarganegaraan membawa pengaruh terhadap proses pengembangan karakter pada setiap peserta didik. Hal ini seperti dimuat beberapa buku Bela Negara yaitu "Penguatan Karakter Remaja”, dimana semua warga negara berhak dan berkewajiban untuk membela negara sesuai bakat masing-masing. ${ }^{1}$ Dan Bela Negara Jilid 2, NKRI dari Perspektif Psikologi dan Pekerja Sosial, yaitu dalam konteks sosial pun, kita bisa berpartisipasi untuk bela negara. ${ }^{2}$ Juga Bela Negara Prespektif Sesuai Profesi, tentu saja berprofesi apa pun kelak, masih bisa berpartisipasi bela negara pada bidang masing-masing sesuai passion. ${ }^{3}$

Bagian dari upaya bela negara adalah kesadaran bela negara yaitu sebuah perilaku yang berlandasarkan pada Pancasila dan UUD 1945 untuk mempertahankan kelangsungan bangsa dan negara. Juga, menjadi modal dasar sekaligus kekuatan bangsa, terutama menjaga keutuhan, kedaulatan, serta kelangsungan hidup bangsa dan negara Indonesia. Melalui budaya sekolah berupa nilai, norma, dan aturan yang terdapat pada kehidupan sekolah, Hal ini akan membentuk kesadaran bela negara. Dengan demikian budaya sekolah dapat membantu membina anak dalam kesadaran bela negara. Taat pada tata tertib, jujur, dan disiplin dan toleransi antar sesama merupakan perilaku siswa yang mencerminkan sadar akan bela negara. Kesimpulannya, nilai-nilai Pancasila dan UUD 1945 dapat diimplementasikan menjadi nilai dalam kehidupan dilingkungan sekolah. Sehingga budaya sekolah dapat membina karakter siswa berupa responsibiliy dan citizenship. ${ }^{4}$

Sebuah hasil pemikiran pengarang dan pujangga Jawa yang sarat akan nilai-nilai adiluhung adalah Karya sastra Jawa. Salah satu diantara karya sastra Jawa tergolong fenomenal dan memuat ajaran moral di dalamnya adalah Serat Tripama karangan KGPAA Mangkunegara IV. Tiga tokoh dalam dunia pewayangan, yang diceritakan pada Serat Tripama yaitu Suwanda, Kumbakarna, dan Karna serta mengandung ajaran mengenai nilai nasionalisme yang tercermin. Sehingga, Serat Tripama bisa dijadikan sarana pengenalan dan penanaman karakter bela negara kepada generasi muda. Mengingat banyaknya generasi muda yang kurang memiliki rasa kecintaan kepada tanah air karena pengaruh masuknya budaya asing. Langkah ini juga dapat digunakan sebagai sarana pengenalan karya-karya sastra Jawa kepada generasi muda, dimana kondisi di era globalisasi seperti sekarang para generasi muda lebih memilih mempelajari budaya dan karya asing daripada belajar dan mengenal budaya sendiri, ${ }^{5}$

Yang mendasari pelaksanaan program bela negara yang dilaksanakan oleh Kementerian

\footnotetext{
${ }^{1}$ Setiyowati, H., Suryaratri, R.D. \& Prihandini, D., 2018

${ }^{2}$ Prihandini, D. \& Setiyowati, H., 2019

${ }^{3}$ Setiyowati, H. et.al., 2021

${ }^{4}$ Widiyanto \& Istiqomah, 2019

${ }^{5}$ Setyawan et al., n.d.
}

Al-Madrasah: Jurnal Ilmiah Pendidikan Madrasah Ibtidaiyah Vol. 6, No. 1, Januari-Maret 2022 
Harlis Setiyowati, Nurhaliza Vania Akbariani : Pengaruh Pendidikan Karakter Bela Negara Terhadap Ancaman Nyata Ke Depan

Pertahanan Republik Indonesia dan seluruh instansi terkait bahwa setiap warga negara wajib mengamankan, melindungi, dan membela negara yang mengancam kedaulatan negara dan keutuhan wilayah. Kewajiban bela negara diemban oleh seluruh masyarakat Indonesia berlandaskan Pancasila, Undang-Undang Dasar 1945, Wawasan Nusantara, dan Ketahanan Nasional. Tidak hanya itu, upaya membela negara bukanlah tugas Tentara Nasional Indonesia (TNI) saja, melainkan seluruh masyarakat Indonesia. Program bela negara tidak bisa dilakukan secara sembarangan, dijalankan secara sistemasis dan terarah melalui jalur pendidikan mengingat pendidikan merupakan ruang dalam pembangunan kesadaran bangsa yang berlandaskan Pancasila dan UUD 1945. Karakter peserta didik perlu dibangun sejak dini sebagai bekal generasi muda penerus bangsa dan negara. ${ }^{6}$

Peserta didik diajak untuk memahami mengenai pengertian, makna, dan tujuan serta urgensi pendidikan kewarganegaraan dalam mengembangkan sikap dan karakter. Dengan demikian Pendididikan Kewarganegaraan berperan penting dalam membangun karakter peserta didik. ${ }^{7}$ Pendidikan Kewarganegaraan juga merupakan salah satu perwujudan karakter masyarakat Indonesia. ADDIE (Analisis, Desain, Pengembangkan, Implementasi, dan Evaluasi), model ini diadopsi pada tahap pengembangan model pembelajaran Pendidikan Kewarganegaraan, dengan modifikasi bernama "MPC" (Modification of Project Citizen). ${ }^{8}$

Pendidikan dimulai dari proses pendidikan serta ide-ide solutif dari berbagai pihak. Pada saat ini bangsa Indonesia mengalami penurunan konsep moral dan mentalitas akan suatu ideologi asli bangsa Indonesia. Pendidikan karakter tepat untuk mengembalikan nilai-nilai kepribadian setiap warga negara, tetapi hal itu harus diapresiasi oleh semua pihak, walaupun hasilnya akan tercapai setelah satu generasi bangsa Indonesia. Dalam rangka membantu peserta didik agar dapat belajar dengan baik dan membentuk manusia Indonesia seutuhnya dalam pembentukan karakter bangsa yang diharapkan mengarah pada penciptaan suatu masyarakat yang menempatkan demokrasi dalam kehidupan berbangsa dan bernegara yang berlandaskan pada Pancasila, UUD dan norma-norma yang berlaku dimasyarakat. Dengan demikian Pembelajaran PKn di sekolah dasar dimaksudkan sebagai suatu proses belajar mengajar. ${ }^{9}$

Sosialisasi dan edukasi terkait pendidikan karakter Bela Negara hendaknya terus disesuaikan dengan berkembangnya era digitalisasi seperti saat ini, termasuk dalam penggunaan telepon pintar berbasis android. Dengan demikian dalam konteks penguasaan teknologi, upaya melakukan pemanfaatan teknologi dan digitalisasi dalam rangka mencegah disinformasi yang bisa

\footnotetext{
${ }^{6}$ Rachmadani Putri et al., 2020

${ }^{7}$ Ratih Setiawati \& Dinie Anggareni Dewi, 2021

${ }^{8}$ Rispantyo, 2019

${ }^{9}$ Nasozaro, 2019
}

Al-Madrasah: Jurnal Ilmiah Pendidikan Madrasah Ibtidaiyah Vol. 6, No. 1, Januari-Maret 2022 
Harlis Setiyowati, Nurhaliza Vania Akbariani : Pengaruh Pendidikan Karakter Bela Negara Terhadap Ancaman Nyata Ke Depan

memicu konflik merupakan bela negara terkini atau yang aktual. Roda disrupsi akan menggerus dan mengganggu seluruh elemen bangsa khususnya generasi muda yang akan menjalankan tongkat estafet di masa mendatang, oleh karena itu, bangsa ini harus mampu beradaptasi dan bersinergi agar tetap menjaga laju pertumbuhan dan pembangunan. Menurut survei Kominfo pada tahun 2017 disebutkan bahwa 66,3\% masyarakat Indonesia sudah memiliki telepon pintar dan akan terus meningkat setiap tahunnya. Dari sekian banyaknya pengguna telopon pintar di Indonesia menurut data statcounter $92 \%$ menggunakan android pada telepon pintar yang dimiliki. Kini, penerapan Teknologi Informasi Dalam Sistem Integrasi Pendidikan Karakter Bela Negara Berbasis Android. Aksi bela negara ditengah terpaan perubahan dunia sudah bukan lagi dilakukan dengan memanggul senjata (hard power), melainkan dengan cara pendekatan soft power yang merupakan perang penguasaan 4C (Critical thinking, Creativity, Collaboration, dan Communication). ${ }^{10}$

Penyelenggaraan pendidikan layanan khusus bagi anak-anak jalanan perlu pendampingan secara terus menerus. Anak jalanan, sangat dinamis atau sering berpindah-pindah dan banyak dari mereka tidak mempunyai identitas diri (KTP). Kaum marginal, kaum yang dianggap memiliki banyak keterbatasan baik secara ekonomi maupun akses. Bahkan keluarga pun mereka tidak punya. Anak jalanan atau anjal kurang diperhatikan sehingga seringkali menyebabkan kekacauan dan mengganggu serta cenderung terjerumus pergaulan bebas juga penggunaan obat terlarang. Sulit mengubah mindset karena pendidikan anak jalanan rendah. Rendahnya keinginan anak mengikuti program pelatihan. Kurangnya dukungan orang tua terhadap program penanganan hingga tingginya tingkat eksploitasi. Sekolah Master dengan dua versi Pendidikan yaitu versi Sekolah Terbuka dan versi PKBM (Pusat Kegiatan Belajar Masyarakat) terdiri dari Paket A, B dan $C$ juga PAUD dan TK. Master singkatan dari Masjid Terminal karena lokasi sekolah berada pada lingkungan terminal Depok dan Masjid tempat awal sebelum memiliki gedung sendiri.

Dengan demikian, peneliti memilih penguatan pendidikan karakter bangsa yang paling tepat yaitu penguatan pendidikan karakter bela negara (PPKBN) dilaksanakan di lingkungan sekolah, lingkungan keluarga, lingkungan masyarakat dan di lingkungan Negara dengan rumusan masalah sebagai berikut :

1. Bagaimana pengaruh pendidikan bela negara di lingkungan sekolah terhadap pengurangan ancaman nyata ke depan pada 'Sekolah Master Depok'?

2. Bagaimana pengaruh pendidikan bela negara di lingkungan keluarga terhadap pengurangan ancaman nyata ke depan pada 'Sekolah Master Depok'?

3. Bagaimana pengaruh pendidikan bela negara di lingkungan masyarakat terhadap

${ }^{10}$ Soedarto \& Aditiawan, 2021

Al-Madrasah: Jurnal Ilmiah Pendidikan Madrasah Ibtidaiyah Vol. 6, No. 1, Januari-Maret 2022 
Harlis Setiyowati, Nurhaliza Vania Akbariani : Pengaruh Pendidikan Karakter Bela Negara Terhadap Ancaman Nyata Ke Depan

pengurangan ancaman nyata ke depan pada 'Sekolah Master Depok'?

4. Bagaimana pengaruh pendidikan bela negara di lingkungan negara terhadap pengurangan ancaman nyata ke depan pada 'Sekolah Master Depok'?

\section{METODE PENELITIAN}

Metode dalam penelitian ini menggunakan pendekatan kuantitatif dengan metode survei. Olah data dilakukan dengan SPSS Versi 25. Adapun kerangka pemikiran dapat digambarkan sebagai berikut:

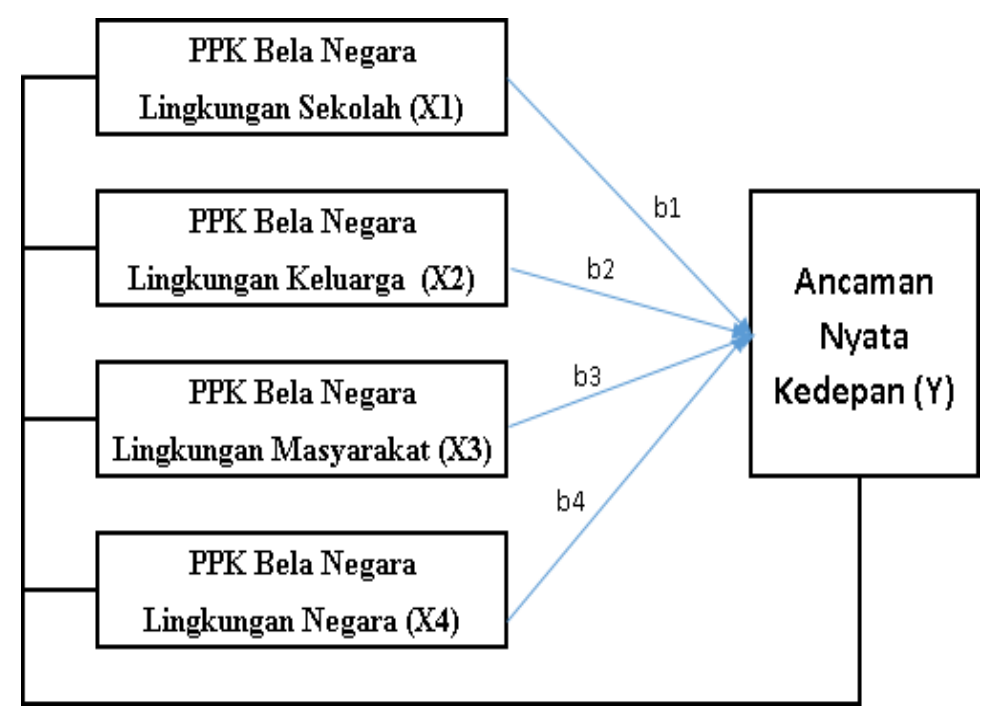

\section{Gambar 1. Kerangka Pemikiran (Sumber : Analisa Penulis)}

\section{Keterangan :}

$\mathrm{X}_{1} \quad$ : Variabel bebas (PPKBN Di Lingkungan Sekolah). $\mathrm{X}_{2} \quad$ : Variabel bebas (PPKBN Di Lingkungan Keluarga).

$\mathrm{X}_{3} \quad$ : Variabel bebas (PPKBN Di Lingkungan Masyarakat). $\mathrm{X}_{4} \quad$ : Variabel bebas (PPKBN Di Lingkungan Negara).

$\mathrm{Y} \quad$ : Variabel terikat (Pengurangan Ancaman Nyata Ke Depan). $b_{1}$ : Koefesien regresi variabel PPKBN Di Lingkungan Sekolah. $b_{2} \quad$ : Koefesien regresi variabel PPKBN Di Lingkungan Keluarga.

$\mathrm{b}_{3} \quad:$ Koefesien regresi variabel PPKBN Di Lingkungan Masyarakat. $b_{4} \quad:$ Koefesien regresi variabel PPKBN Di Lingkungan Negara.

R2 : Koefesien determinasi variabel PPKBN Di Lingkungan Sekolah, PPKBN Di LingkunganKeluarga, PPKBN Di Lingkungan Masyarakat dan PPKBN Di Lingkungan Negara. 
Harlis Setiyowati, Nurhaliza Vania Akbariani : Pengaruh Pendidikan Karakter Bela Negara Terhadap Ancaman Nyata Ke Depan

Berikut pemetaan PPKBN sebagai alat ukur penelitian :

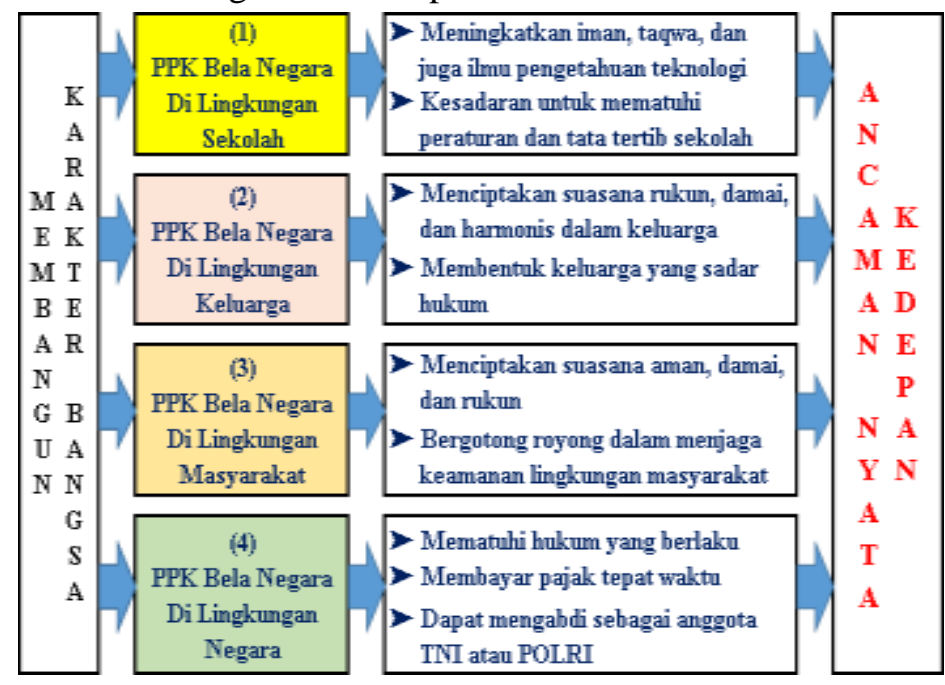

\section{Gambar 2. Penguatan Pendidikan Karakter Bela Negara Sumber : diolah oleh penulis}

\section{HASIL DAN PEMBAHASAN}

Teknik pengumpulan data melalui penyebaran daftar pernyataan (kuesioner) sebanyak 10 butir instrument pilihan ganda untuk variabel $\mathrm{X}_{1}$ dengan kriteria penilaian $0=$ jika jawaban salah dan 1 = jika jawaban benar. Untuk variabel $\mathrm{X}_{2}, \mathrm{X}_{3}, \mathrm{X}_{4}$ dan variabel $\mathrm{Y}$ masing-masing 6 butir instrument dengan sampel sebanyak 40 orang. Perhitungan selanjutnya, seluruh angket yang masuk disusun ke dalam format rekapitulasi skor jawaban melalui proses tabulasi data dan setiap alternative jawaban diberi bobot berjenjang, (Skala likkert).

\section{a) Hasil Uji F}

Nilai $\mathrm{F}$ hitung > F tabel, sehingga $\mathrm{Ho}$ ditolak dan $\mathrm{H}_{\mathrm{a}}$ diterima. Hasil diperoleh nilai $\mathrm{F}$ hitung sebesar 536,086, sedangkan besarnya F tabel dengan derajat bebas (df) 40 dan 40 pada $\alpha$ $(0,05)$ sebesar 2,49. Hal ini dinyatakan bahwa variabel PPKBN Di Lingkungan Sekolah $\left(\mathrm{X}_{1}\right)$, PPKBN Di Lingkungan Keluarga $\left(\mathrm{X}_{2}\right)$, PPKBN Di Lingkungan Masyarakat $\left(\mathrm{X}_{3}\right)$, PPKBN Di Lingkungan Negara $\left(\mathrm{X}_{4}\right)$ secara bersama-sama berpengaruh nyata terhadap Pengurangan Ancaman Nyata Ke Depan (Y), dan hipotesis terbukti.

\section{b) Hasil Uji t}

Uji t dilakukan untuk mengetahui besar kecilnya pengaruh variabel bebas secara individu terhadap variabel terikat $(Y)$. Nilai $t$ hitung $>\mathrm{t}$ tabel, sehingga $\mathrm{H}_{\mathbf{o}}$ ditolak dan $\mathrm{H}_{\mathbf{a}}$ diterima dengan derajat bebas (df) 40 pada $\alpha(0,05)$ sebesar 2,030. Dari hasil pengolahan data penelitian untuk keempat pengujian diperoleh nilai t hitung sebagai berikut: 
Harlis Setiyowati, Nurhaliza Vania Akbariani : Pengaruh Pendidikan Karakter Bela Negara Terhadap Ancaman Nyata Ke Depan

\section{1) Untuk Variabel PPKBN Di Lingkungan Sekolah $\left(X_{1}\right)$,}

Diperoleh nilai t hitung sebesar 2,797, sehingga dapat dinyatakan bahwa PPKBN Di Lingkungan Sekolah $\left(\mathrm{X}_{1}\right)$ secara individual berpengaruh nyata terhadap Pengurangan Ancaman Nyata Ke Depan (Y), dan hipotesis terbukti.

\section{2) Untuk Variabel PPKBN Di Lingkungan Keluarga $\left(\mathrm{X}_{2}\right)$.}

Diperoleh nilai t hitung sebesar 2,165, sehingga $\mathrm{H}_{\mathbf{0}}$ ditolak dan $\mathrm{H}_{\mathbf{a}}$ diterima. Sehingga dapat dinyatakan bahwa PPKBN Di Lingkungan Keluarga $\left(\mathrm{X}_{2}\right)$ secara individual berpengaruh nyata terhadap Pengurangan Ancaman Nyata Ke Depan (Y), dan hipotesis terbukti.

3) Untuk Variabel PPKBN Di Lingkungan Masyarakat $\left(X_{3}\right)$.

Diperoleh nilai thitung sebesar 11,634, sehingga dapat dinyatakan bahwa PPKBN Di Lingkungan Masyarakat $\left(\mathrm{X}_{\mathbf{3}}\right)$ secara individual berpengaruh nyata terhadap Pengurangan Ancaman Nyata Ke Depan (Y), dan hipotesis terbukti.

\section{4) Untuk Variabel PPKBN Di Lingkungan Negara $\left(\mathrm{X}_{4}\right)$.}

Diperoleh nilai t hitung sebesar 4,524, sehingga dapat dinyatakan bahwa PPKBN Di Lingkungan Negara $\left(\mathrm{X}_{4}\right)$ secara individual berpengaruh nyata terhadap Pengurangan Ancaman Nyata Ke Depan (Y), dan hipotesis terbukti.

\section{c) Hasil Uji Koefisien Determinasi $\left(\mathbf{R}^{2}\right)$}

Uji Koefisien determinasi digunakan untuk mengetahui tingkat keragaman variabel terikat $Y$ yang disebabkan oleh keragaman variabel bebas. Pengolahan data hasil penelitian diperoleh nilai $\mathrm{R}^{2}$ sebesar 0.984. Artinya bahwa sebesar 98,40 \% keragaman Pengurangan Ancaman Nyata Ke Depan (Y) disebabkan oleh keragaman PPKBN Di Lingkungan Sekolah $\left(\mathrm{X}_{1}\right)$, variabel PPKBN Di Lingkungan Keluarga $\left(\mathrm{X}_{2}\right)$, PPKBN Di Lingkungan Masyarakat $\left(\mathrm{X}_{3}\right)$,

PPKBN Di Lingkungan Negara $\left(\mathrm{X}_{4}\right)$ sedangkan sisanya 1,60\% disebabkan oleh faktor-faktor lain.

\section{d) Hasil Uji Persamaan Regresi Berganda (Y).}

Persamaan regresi berganda merupakan model persamaan garis untuk melihat pengaruh variabel X terhadap variabel Y. Dari hasil pengolahan komputer berdasarkan perhitungan SPSS, pada penelitian ini diperoleh hasil sebagai berikut:

$$
Y=0,231+0,099 X_{1}+0,099 X_{2}+0,698 X_{3}+0,202 X_{4}
$$

Persamaan ini berarti bahwa: konstanta sebesar 0,231 menyatakan bahwa jika tidak ada PPKBN Di Lingkungan Sekolah, PPKBN Di Lingkungan Keluarga, PPKBN Di Lingkungan Masyarakat, PPKBN Di Lingkungan Negara atau secara matematis $\mathrm{X}_{\mathbf{1}}, \mathrm{X}_{\mathbf{2}}, \mathrm{X}_{\mathbf{3}}$ dan $\mathrm{X}_{\mathbf{4}}$ adalah 0 
Harlis Setiyowati, Nurhaliza Vania Akbariani : Pengaruh Pendidikan Karakter Bela Negara Terhadap Ancaman Nyata Ke Depan

maka "Pengurangan Ancaman Nyata Ke Depan" (Y) sebesar 0,231.

Setiap peningkatan 1 skor variabel PPKBN Di Lingkungan Sekolah $b_{1}=0,099$, berpengaruh nyata terhadap peningkatan variabel "Pengurangan Ancaman Nyata Ke Depan" (Y) sebesar 0, 099 dengan asumsi variabel PPKBN Di Lingkungan Keluarga $\left(\mathrm{X}_{2}\right)$, PPKBN Di Lingkungan Masyarakat $\left(\mathrm{X}_{3}\right)$ dan PPKBN Di Lingkungan Negara $\left(\mathrm{X}_{4}\right)$ nilainya konstan. Setiap peningkatan 1 skor variabel PPKBN Di Lingkungan Keluarga $b_{2}=0,099$ berpengaruh nyata terhadap peningkatan variabel Pengurangan Ancaman Nyata Ke Depan (Y) sebesar 0,099 dengan asumsi variabel PPKBN Di Lingkungan Sekolah $\left(\mathrm{X}_{\mathbf{1}}\right)$, PPKBN Di Lingkungan Masyarakat $\left(\mathrm{X}_{\mathbf{3}}\right)$ dan PPKBN Di Lingkungan Negara $\left(\mathrm{X}_{4}\right)$ nilainya konstan.

Setiap peningkatan 1 skor variabel PPKBN Di Lingkungan Masyarakat $b_{3}=0,698$ berpengaruh nyata terhadap peningkatan variabel Pengurangan Ancaman Nyata Ke Depan (Y) sebesar 0,698 dengan asumsi variabel PPKBN Di Lingkungan Sekolah (X) , variabel PPKBN Di Lingkungan Keluarga $\left(\mathrm{X}_{2}\right)$ dan PPKBN Di Lingkungan Negara $\left(\mathrm{X}_{4}\right)$ nilainya konstan.

Setiap peningkatan 1 skor variabel PPKBN Di Lingkungan Negara $b_{4}=0,202$ berpengaruh terhadap nyata peningkatan variabel Pengurangan Ancaman Nyata Ke Depan (Y) sebesar 0,202 dengan asumsi variabel PPKBN Di Lingkungan Sekolah ( $\mathrm{X}_{1}$ ), variabel PPKBN Di Lingkungan Keluarga $\left(\mathrm{X}_{2}\right)$ dan PPKBN Di Lingkungan Masyarakat $\left(\mathrm{X}_{3}\right)$ nilainya konstan.

\section{KESIMPULAN}

Kegiatan untuk membantu perkembangan peserta didik mencapai tujuan pendidikan diatur dalam Undang-Undang Republik Indonesia Nomor 20 Tahun 2003 tentang Sistem Pendidikan Nasional mengartikan pendidikan adalah usaha sadar dan terencana untuk mewujudkan suasana belajar dan proses pembelajaran agar peserta didik secara aktif mengembangkan potensi dirinya untuk memiliki kekuatan spiritual keagamaan, pengendalian diri, kepribadian, kecerdasan, akhlak mulia serta keterampilan yang diperlakukan dirinya, masyarakat, bangsa, dan negara.

Hasil pengolahan data diperoleh nilai $\mathrm{F}$ hitung > F tabel, dapat dinyatakan bahwa variabel PPKBN Di Lingkungan Sekolah $\left(\mathrm{X}_{1}\right)$, variabel PPKBN Di Lingkungan Keluarga $\left(\mathrm{X}_{2}\right)$, variabel PPKBN Di Lingkungan Masyarakat $\left(\mathrm{X}_{3}\right)$, variabel PPKBN Di Lingkungan Negara $\left(\mathrm{X}_{4}\right)$ secara bersama-sama berpengaruh nyata terhadap Pengurangan Ancaman Nyata Ke Depan (Y) dan hipotesis terbukti. Hal ini menunjukkan secara empirik bahwa perwujudan PPKBN Di Lingkungan Sekolah, PPKBN Di Lingkungan Keluarga, PPKBN Di Lingkungan Masyarakat dan PPKBN Di Lingkungan Negara mendapat dukungan baik dari pemerintah maupun masyarakat sehingga memiliki relevansi yang sangat kuat dengan kualitas Pengurangan Ancaman Nyata Ke Depan. 
Harlis Setiyowati, Nurhaliza Vania Akbariani : Pengaruh Pendidikan Karakter Bela Negara Terhadap Ancaman Nyata Ke Depan

PPKBN Di Lingkungan Sekolah $\left(\mathrm{X}_{1}\right)$, PPKBN Di Lingkungan Keluarga $\left(\mathrm{X}_{2}\right)$, PPKBN Di Lingkungan Masyarakat $\left(\mathrm{X}_{\mathbf{3}}\right)$ dan PPKBN Di Lingkungan Negara $\left(\mathrm{X}_{\mathbf{4}}\right)$ dimana masing-masing secara individual berpengaruh nyata terhadap Pengurangan Ancaman Nyata Ke Depan (Y) dan hipotesis terbukti.

Koefisien determinasi berganda $\left(\mathrm{R}^{2}\right)$, diperoleh nilai $\mathrm{R}^{2}$ sebesar 0.984. Artinya bahwa sebesar 98,40\% keragaman Pengurangan Ancaman Nyata Ke Depan (Y) disebabkan oleh keragaman PPKBN Di Lingkungan Sekolah $\left(X_{1}\right)$, variabel PPKBN Di Lingkungan Keluarga $\left(X_{2}\right)$, PPKBN Di Lingkungan Masyarakat $\left(\mathrm{X}_{3}\right)$ dan PPKBN Di Lingkungan Negara $\left(\mathrm{X}_{4}\right)$ sedangkan sisanya $1,60 \%$ disebabkan oleh faktor-faktor lain.

\section{SARAN dan REKOMENDASI}

Dikarenakan nilai beta coefficient variabel PPKBN Di Lingkungan Masyarakat $\left(\mathrm{X}_{3}\right)$ lebih besar dari variabel PPKBN Di Lingkungan Negara $\left(\mathrm{X}_{4}\right)$, diikuti oleh variabel PPKBN Di Lingkungan Sekolah $\left(\mathrm{X}_{1}\right)$ dan variabel PPKBN Di Lingkungan Keluarga $\left(\mathrm{X}_{2}\right)$. Oleh karena itu konsep Pengurangan Ancaman Nyata Ke Depan (Y) seyogyanya sejalan dengan kualitas PPKBN Di Lingkungan Masyarakat. Semakin tinggi kualitas PPKBN Di Lingkungan Masyarakat maka diyakini memiliki relevansi yang sangat kuat dengan tingginya kualitas pengurangan Ancaman Nyata Ke Depan (Y) itu sendiri. Begitu juga sebaliknya, jika proses PPKBN Di Lingkungan Masyarakat itu masih lemah atau dalam kata lain partisipasi yang belum optimal, akan mencerminkan kualitas Pengurangan Ancaman Nyata Ke Depan (Y) yang juga lemah.

Selain pemberian modul dan pelatihan pada PPKBN di lingkungan sekolah dengan menekankan pada kegiatan pembelajaran PKn, kegiatan ekstrakurikuler dan kokurikuler. Kelak harus ada penelitian dengan pendekatan penelitian kuantitatif dengan metode intervensi yaitu PPKBN di lingkungan masyarakat yang bertujuan menekankan pada kegiatan ketrampilan wirausaha seperti menjahit, memasak, menyulam dll. Hal ini akan bisa membantu ekonomi keluarga dan kesejahteraan akan terjamin. Termasuk perlunya diklat bela negara untuk masyarakat.

\section{DAFTAR PUSTAKA}

https://doi.org/10.31316/jk.v5i1.1452 Jurnal Warta, 62, 24-33.

Kementerian Pendidikan dan Kebudayaan RI, (2010). Â Pengembangan Pendidikan Budaya dan Karakter Bangsa. Jakarta: Kementerian Pendidikan Nasional.

Nasozaro, H. O. (2019). Pembangunan Karakter Bangsa Melalui Pendidikan kewarganegaraan.

PADA GENERASI MILLENIAL DI INDONESIA Azizoel Metiadini Hayatul Khairul Rahmat Arifuddin Uksan. Jurnal Ilmu-Ilmu Sosial Dan Keislaman Issn, 5(2), 2528-2492.

Al-Madrasah: Jurnal Ilmiah Pendidikan Madrasah Ibtidaiyah Vol. 6, No. 1, Januari-Maret 2022 
Harlis Setiyowati, Nurhaliza Vania Akbariani : Pengaruh Pendidikan Karakter Bela Negara Terhadap Ancaman Nyata Ke Depan

http://dx.doi.org/10.31604/muaddib.v5i1.257-271

Prihandini, D. \& Setiyowati, H. (2019). Bela Negara Jilid 2, NKRI dari Perspektif Psikologi dan Pekerja Sosial. Yayasan Keluarga Haerhave.

Rachmadani Putri Magister Manajemen Pertahanan, H., Manajemen Pertahanan, F., Manajemen Pertahanan, M., Manajemen Bencana, M., \& Keamanan Nasional, F. (2020). URGENSI PENDIDIKAN BELA NEGARA GUNA MEMBANGUN SIKAP NASIONALISME

Ratih Setiawati \& Dinie Anggareni Dewi. (2021). Pengembangan Karakter Pada Peserta Didik Melalui Pendidikan Kewarganegaraan. EDUCATIONAL : Jurnal Inovasi Pendidikan \& Pengajaran, 1(2), 92-98. https://doi.org/10.51878/educational.v1i2.204

REPRESENTASI KARAKTER BELA NEGARA DALAM SERAT TRIPAMA SEBAGAI SARANA PENDIDIKAN KARAKTER KEPADA SISWA. 3(1), 1-11.

Rispantyo, A. T. S. \&. (2019). Implementasi Pendidikan Karakter Dalam Pendidikan Kewarganegaraan Sebagai Inovasi Pengembangan Di Era Media Digital Dan Revolusi Industri 4.0. Jurnal Global Citizen : Jurnal Ilmiah Kajian Pendidikan Kewarganegaraan, 7(1). https://doi.org/10.33061/jgz.v7i1.3059

Setiyowati, H. , Suryaratri, R.D. \& Prihandini, D. (2018). Bela Negara "Penguatan Karakter Remaja" Rafikatama Jakarta.

Setiyowati, H. et.al. (2021). Bela Negara Prespektif Sesuai Profesi. Yayasan Keluarga Haerhave. Setyawan, B. W., Mulyaningtyas, R., Rohmadi, M., Maret, U. S., \& Tengah, J. (n.d.).

Sianturi, Y. R. U., \& Dewi, D. A. (2021). Penerapan Nilai Nilai Pancasila Dalam Kehidupan Sehari Hari Dan Sebagai Pendidikan Karakter. Jurnal Kewarganegaraan, 5(1), 222-231.

Soedarto, T. \&, \& Aditiawan, F. P. (2021). Penerapan Teknologi Informasi Dalam Sistem Integrasi, Karakter Pendidikan Bela Negara Berbasis Android. XVI, 22-25.

Soepandji, K. W., \& Farid, M. (2018). Konsep Bela Negara Dalam Perspektif Ketahanan Nasional. Jurnal Hukum \& Pembangunan, 48(3), 436. https://doi.org/10.21143/jhp.vol48.no3.1741

Umra, S. I. (2019). Penerapan Konsep Bela Negara, Nasionalisme Atau Militerisasi Warga Negara. Jurnal Lex Renaissance, 4(1), 164-178. https://doi.org/10.20885/jlr.vol4.iss1.art9

Undang-Undang Dasar Negara Republik Indonesia tahun 1945. Undang-Undang No. 3 tahun 2002, tentang Pertahanan Negara.

Widiyanto, D., \& Istiqomah, A. (2019). Pembinaan Kesadaran Bela Negara Melalui Budaya $\begin{array}{lllll}\text { Sekolah. Jurnal Pendidikan } & \text { Kewarganegaraan, }\end{array}$ https://doi.org/10.31571/pkn.v3i2.1436

Widodo, Joko (Presiden RI), Sambutan Presiden Republik Indonesia pada Upacara Peringatan Hari Bela Negara tahun 2014.

Al-Madrasah: Jurnal Ilmiah Pendidikan Madrasah Ibtidaiyah Vol. 6, No. 1, Januari-Maret 2022 